NBER WORKING PAPER SERIES

RULES AND DISCRETION IN TRADE POLICY

Robert W. Staiger

Guido Tabellini

Working Paper No. 2658

NATIONAL BUREAU OF ECONOMIC RESEARCH 1050 Massachusetts Avenue

Cambridge, MA 02138

July 1988

We are grateful to Peter Neary and to two anonymous referees for very helpful comments on a previous version. This research is part of NBER's research program in International Studies. Any opinions expressed are those of the authors not those of the National Bureau of Economic Research. 
NBER Working Paper \#2658

July 1988

\section{RULES AND DISCRETION IN TRADE POLICY}

\section{ABSTRACT}

We argue in this paper that the second-best nature of trade-policy intervention makes it likely that the issue of time consistency will be an important consideration in determining both the extent and the efficacy of such intervention in most er.vironments. The point is seen most directly by noting that a tariff is both a tax on consumers and a subsidy to producers of the import-competing good. Since first-best intervention typically calls for targeting each distortion with a separate tax/subsidy, the tariff will be a more effectlve policy tool if its consumption tax aspect can be separated from its production subsidy dimension. Consequently, if production decisions are made prior to consumption decisions, a government with sufficient policy flexibility will be tempted to surprise producers with policies other than those announced in an effort to make this separation. This leads optimal trade policy intervention to be time-inconsigtent in a wide range of environments. We explore this idea in general terms and illustrate the results with specific examples.

Robert W. Staiger Department of Economics Stanford University Stanford, CA 94305
Guido Tabellini

Department of Economics

U.C.L.A.

Los Angeles, CA 90024 


\section{Introduction}

Since the publication of the seminal paper of Kydland and Prescott (1977) on the time inconsistency of optimal policy, the debate over rules versus discretion has had a major influence on the evolution of ideas concerning macroeconomis policy. In contrast, this debate has had comparatively little effect on the international trade literature, where discussion concerning the efficacy of activist trade policy in general and the relative merits of alternative trade policies in particular has proceeded iargely under the (implicit) assumption that governments can precommit to the optimal policy.

Yet the question of the costs of discretion in trade policy deserves serious attention, especially in light of the recent literature on trade in the presence of imperfect markets. While much of this literature is concerned with various conditions under which activist trade policies are warranted, taken together the results of the literature suggest a second, more subtle, implication: the new activist trade policy, if it is to be pursued at all, must be pursued with discretion and flexibility, judging each situation on a case by case basis.' such, the current debate over the appropriate degree of activism in trade policy is unavoidably a debate over the appropriate degree of polfcy discretion as well.

The relevance for trade policy of the debate on rules versus discretion is also suggested by the following consideraticn: a necessary condition for any economic policy to be time inconsistent is that the government implementing that policy find itself in a second best (or worse) situation. This condition is virtually always satisfied in the case of trade policy: if the government is forced to rely on tariffs to achieve its objectives, it is because it lacks 
other, less distortionary, instruments. 2/ In this environment, unexpected policy actions can enlarge the set of instruments available to the government. Hence, if a government using trade policy had the option of surprising the private sector with unexpected policies, it would choose to do so since a policy surprise could move the economy towards the first best. In other words, with a sufficient degree of discretion and flexibility, the optimal trade policy is bound to be time inconsistent.

The central results of this paper are based on the idea that governments often enjoy sufficient discretion to generate trade policy surprises with respect to production decisions, but not with respect to consumption decisions. While decisions concerning the allocation of consumption across different commodities are generally fairly flexible, decisions concerning investment or resource allocation are often much less so. Hence, in the presence of sufficient government flexibility, the latter decisions might have to be made before observing trade policy actions. When this is the case, production decisions must be based on the expectations of forthcoming trade policies, and the government has the option of generating policy surprises. Of course, in equiliorium policy surprises are ruled out by an incentive compatibility condition. This condition implies that the government loses control of producers' expectations. Thus, in an equilibrium with discretion, the government is prevented from taking into account the production distortions induced by the expectation of future trade policy.

The next section develops the normative and positive Implications of this idea. Sections III and IV illustrate these general results with specific 
examples. Possible extensions and generalizations are discussed in Section $V$. Finally, Section VI concludes the paper.

\section{I Time Inconsistency and Trade Policy}

Consider the basic trade model of a static economy in which all goods are traded and individuals act as producers and/or consumers. The arguments of this and of the next two sections hinge on the following crucial timing assumption: Eirst, producers select the allocation of productive resources, 1.e. they select a point on the (possibly distorted) production possibility frontier. $\underline{3}$ ' Next (or simultaneously with the producers), the government chooses its tariff policy. Einally, consumers make their consumption decisions. This is equivalent to assuming that the government has at least as much flexibility in choosing the level of its tariff as does the private sector in choosing the sectoral allocation of resources, but that consumer decisions are the most flexible of all. Clearly this is not always the case in practice; but the assumption seems to capture the relative timing of moves for the three $k i n d s$ of agents in a broad class of environments, provided that the government is endowed with sufficiently flexible trade policy instruments. For instance, such flexibility might characterize escape clause actions under section 201 of the Trade Act of 1974. The implications of relaxing this timing assumption are discussed in section $V$ below.

The importance of the timing assumpticn is immediate once it is recalled that a tariff can always be decomposed into a domestic production subsidy and a domestic consumption tax on the domestic import good. The timing assumption implies that, in equilibrium, the government is forced to take producers' 
decisions as bygones when choosing its trade policy. Hence, the government ignores any production distortions introduced by the production tax/subsidy aspect of its tariff policy: the tariff is set as if the distortions it brought about were only those associated with the consumption tax/subsidy dimension. But of course, the expectation of the forthcoming tariff policy exerts an influence on the production side of the economy, even if in equilibrium the government is prevented from taking this into account.

We now explore this idea in general terms, turning to specific illustrative examples in the following sections. To begin we consider an environment in which lump sum instruments are available to redistribute income, so that the domestic government is concerned only with the conditions of Pareto efficiency. We explore the time-inconsistency issues that arise when the government attempts to use trade policy (a tariff) to of fset existing distortions.

(i) Consider first the existence of a domestic production distortion. A production tax/subsidy can move the economy toward (possibly to) the Pareto frontier, but a consumption tax/subsidy will only move it further away. Thus, regardless of the (ex-ante) tariff policy announced to producers, once production decisions are made, the government faces a new (ex-post) optimization problem: set the tariff level so that the consumption tax implicit in it maximizes welfare (achieves Pareto efficiency) in a small exchange economy with no distortions. The resulting equilibrium policy is clearly free trade, even though the (secondbest or worse) optimal tariff policy is typically not free trade. $\underline{5}$ Hence, in the presence of policy discretion, trade policy will be under utilized as a (secondbest or worse) tool to address production distortions: in such an environment, the unique time-consistent equilibrium is one of free trade. Section III below 
provides an illustration of this case.

(ii) Consider next the existence of a domestic consumption distortion. Here a consumption tax/subsidy can move the country to the pareto frontier, but a production tax/subsidy must move it further away. Again, independent of the (exante) tariff policy announced to producers, once production decisions are nade, the government faces a new (ex-post) optinization problem: set the tariff level so that the consumption tax implied therein maximizes welfare (achieves Pareto efficiency) in a small exchange economy with a domestic consumption distortion. Here the time-consistent policy is clearly to set the tariff at a level which exactly offsets the domestic consumption distortion, even though the (secondbest) optimal tariff will stop short of this because of the production distortions introduced by the tariff. $6 /$ Thus, the use of trade policy as a (second-best) tool to address domestic consumption distortions when the government has policy discretion will be excessive.

(iii) Finally, consider the existence of a trade distortion. The relevant point here is that a tariff now also affects foreign production and consumption decisions. In choosing a tariff, the domestic government must weigh the benefits of tariff revenue againgt the costs of the distorted producer and consumer decisions in the domest1c economy. At the (ex-ante) optimum tariff, a small increase in the tariff would lead to an increase in tariff revenue whose benefits are just offset by the costs of increasing distortions at home. However, once domestic and foreign production decisions are made, domestic and foreign production responses to further tariff changes disappear, and a small increase in the tariff starting from the (ex-ante) optimum will increase tariff revenue by more than the cost of the increased distortion at home. Hence, the time- 
consistent tariff in this case involves excessive protection. This point has been made by Lapan (forthcoming). I'

(iv) Thus far we have maintained the assumption that lump sum redistributive instruments are available and have explored the nature of timeconsistent trade policy when one of the conditions for Pareto efficiency is violated. Consider now the case in which all the conditions for Paretio efficiency hold but the government wishes to redistribute income and does not have access to lump sum tax instruments. In this case the government would like to leave all economic decisions undistorted but at the same time desires to alter the distribution of income. The (ex-ante) optimal use of a tariff would at the margin weigh the redistributive benefits against the costs of domestic producer and consumer distortions. However, once producer decisions are made, the (expost) redistributive effects of an additional increase in the tariff will in general differ from the effects ex-ante, and the associated benefits may rise or fall. Moreover, these benefits will be weighed only against the additional consumer distortions induced. Hence, when the government has policy discretion, trade policy may be over- or under-utilized as a redistributive tool. Section II below illustrates a case in which policy is over-utilized with an example taken from staiger-Tabellini (1987).

We summarize these results in the following:

Proposition: When the degree of flexibility in government trade policy decision making is greater (less) than it is in the resource allocation (consumption) decisions of the private sector, tariffs will be under utilized relative to their optimal use in the presence of domestic production distortions, over utilized relative to their optimal use in the presence of domestic consumption distortions and trade distortions, and either under- or over-utilized relative to their optimal use as redistributive tools. 
Three implications emerge from this general analysis. First, because trade policy distorts the decisions of both producers and consumers and because the decisions of the former typlcally preceed those of the latter, sufficient government flexibility is likely to undermine the optimal use of trade policy as a remedy for the existence of distortions. That is, optimal trade policy in this broad class of problems will in general be time-inconsistent. Whenever this is the case, rules may be better than discretion in the conduct of trade policy. second, given that optimal trade policy is generally time-inconsistent in this environment, policy rankings that acknowledge this time-inconsistency will generally differ from the analogous rankings based on the optimal (timeinconsistent) tariff. Finally, with the existence of domestic consumption distortions considered to be empirically unimportant as a trade policy rationale (see Bhagwati, 1968), Our results suggest that a government with policy discretion will use tariffs primarily in two cases: either as redistributive tools, or where it has world market power. In the next two sections we lilustrate the general conclusions drawn here with specific examples.

\section{Over-Active Pollcies}

We consider first a two-sector model in which tariffs are used by the government to redistribute income from individuals with a low marginal utility of income to those with a high marginal utility of income, subsequent to the realization of an adverse terms of trade shock. In order to focus on the issue of precommitment, we suppose that the government is benevolent and maximizes a social welfare function defined over the utility of the workers in both sectors. In the absence of complete insurance markets, the government may wish 
to use trade policy to reduce intersectoral wage differentials that arise as a result of the shock.,

In particular, we start with a small open economy producing two traded goods, $x$ and $y$, using one input, labor. Suppose that labor can move across sectors, but only at a cost. Specifically, assume that whenever a worker changes sectors, its marginal product falls by the fraction $1-\lambda, 1>\lambda>0$. Consider now what happens if the world price of the imported good, say $y$, drops unexpectedly. If it drops by more than $(1-\lambda)$, some fraction $(1-y)>0$ of sector $y^{\prime} s$ work force will find it worthwhile to relocate across sectors. The post-shock equilibrium allocation of laoor is lllustrated by the intersection of the solid lines in Figure 1, under the assumptions that the production function is concave and that the government does not (and is not expected to) intervene with trade protection. The horizontal axis measures $Y$, the fraction of sector $y^{\prime} s$ pre-shock labor force that remains in the injured sector. The vertical axis measures the wage in sector $y$ and $\lambda$ times the wage rate in sector $x . t^{e}$ denotes the expected degree of tariff protection. Given the concavity of the production function, the wage in sector $y\left(w_{y}\right)$ is decreasing in the fraction of workers who remain in that sector ( $Y$ ) and is represented by a downward sloping schedule in Figure 1. Conversely, wx is increasing with $Y$, and $\lambda w_{x}$ is given by the upward sloping schedule in Eigure 1 . The equilibrium allocation of labor when protection is neither expected nor forthcoming is $Y^{*}\left(t^{e}=0\right)$, and corresponds to the point where the wage differential between the two sectors is exactly equal to the cost of relocating: $\frac{w}{w}=\lambda$. 
Now consider the actions of the government. As noted at the outset, the government may wish to use trade policy to reduce the wage differential between the two sectors. However, the actual redistribution associated with any given tariff depends on the fraction of workers remaining in the injured sector ( $Y$ ), which depends in turn on the expected tariff. As such, unexpected protection can nave effects quite apart from protection that is fully anticlpated by the work force. This is why the issue of time inconsistency arises: the government may have an incentive to surprise the private sector by providing more protection than expected.

In order to see that this is the case, consider what happens to the diagram of Figure 1 if workers anticipate the protective policy. An increase in the degree of protection forthcoming would shift the $w_{y}$ curve to the right--say, to the dotted line of Figure 1 , where $t=t>0$. With the tariff fully anticipated $\left(t^{e}=\bar{t}\right)$, the fraction of labor staying in the $y$ sector in equilibrium is now $\left.\gamma^{* *\left(t^{e}\right.}=\bar{t}\right)>Y^{*}\left(t^{e}=0\right)$, and the equilibrium wage differential remains $\frac{w^{y}}{w^{x}}=\lambda$. Intultively, if workers realize that the protective policy is forthcoming, they will reduce their reallocation away from the injured sector. Under our hypothesis, a perfectly anticipated protective policy would have no impact on the wage dif:erential, but would simply bring about an inefficlent allocation of labor. If however, the protective policy were unexpected, then it would take the economy to point A in Flgure 1: the labor allocation would remain unaffected, and all the impact of the policy would be on the wage differential. Hence the government's incentive to surprise. Since the government is not able systematically to deselve the private sector, the (time consistent) equilibrium is found where the government's incentive to surprise is 
Just equal to the marginal cost of the consumption distortions associated with a higher tariff.

In Staiger and Tabellini (1987), we show that in such an equilibrium the tariff is always positive, even though the optimal trade policy may be one of free trade. Hence, the requirement of time consistency implies in this case that governments with some degree of discretion in trade policy may be forced to choose inferior over-protective policies. This comes about not as a result of lobbying pressures or other political concerns. Rather, it is a consequence of the government's inability to precommit to trade policies which it would not, once the labor force has reallocated, care to pursue. Moreover, the requirement of time consistency can lead to a reversal of the traditional normative orderings of tariffs and subsidies as instruments of trade policy. Since a production subsidy is not associated with any consumption distortions, there is a greater incentive to utilize it as a surprise policy tool. Consequently, its time consistent level would always be higher than that of a time consistent tariff. As a result, in a time consistent equilibrium a policy of production subsidies may be welfare-dominated by a tariff.

\section{Pareto Inferior Trade}

In this section, we explore the use of trade policy to address a distortion that arises in the allocation of productive resources between a safe and a risky sector. Speciflcally, consider a two-country two-sector model with one safe and one risky sector. In the presence of production risk that is not perfectly positively correlated across countries, trade policy decisions will affect the extent to which prices adjust in response to variations in output. As such, 
trade pollcy w111 affect the degree of risk borne by producers, and the allocation of productive resources between risky and non-risky sectors. Consumers w11l be affected by trade policy in two ways: directly via the effect of policy on the risk (price varlability) they race, and indirectly via the sectoral relocation of productive resources.

Newbery and Stiglitz (1984) explore these issues with a simple model in whlch the opportunity to trade goods internationally completely stabilizes goods prices. In their odel, trade leaves producers earning the same expected return but racing greater risk than in autarky, while consumers enjoy reduced risk but suffer a divergence of the resource allocation away from their preferred pattern. Risk averse producers are unamblguously worse of with trade in this model while the risk aversion of consumers makes the reduction in risk they face a benefit from trade that wust be weighed against the consumer loss associated with relocation of productive resources. For some parameter values, Newbery and Stiglitz show that the opportunity to trade can lead to a Pareto inferior outcome. We explore a simllar setup and show that, when the government has more flexiblitity than the production sector and finds pollcy commitments infeasible, it will be unable to use trade pollcy to keep the economy from the Pareto inferior free trade equilibrium.

Following Newbery and Stiglitz, we consider two countries--home (no star) and forelgn (star)--both of whlch use "capital" to produce a risky good and a safe good. Each country has $n$ Identical producers, each owning one unit of capltal, and in ldentical consumers, each with a constant amount of income I, whlch can be thought of as their endowment of a third (numeraire) good. The output of the risky good is perfectly negatively correlated across countries: 
that is, if output per unit of capital of the risky good is $\theta$, a random variable with mean unity and variance $\sigma^{2}$, then $\theta+\theta^{*}=2$. The output of the safe good per unit of capital is normalized to unity.

As in Newbery and Stiglitz, we consider only symmetric equilibria in which the domestic and foreign choices coincide. We will focus on the decisions of domestic producers and consumers. Competitive risk averse producers choose a fraction $x$ of their capital to allocate to the $r i s k y$ project, the remainder $(1-x)$ going to produce the safe good. Assuming that producers do not consume what they produce and that they maximize expected utility of profits, the choice of $x$ will be given by the solution to

$$
E U^{\prime}(\pi)(p \Theta-q)=0
$$

where $p(q)$ is the price of the risky (safe) good, $\Pi=x p \theta+q(1-x$ ) are producer profits, and $E U(\pi)$ is the expected utility of profits with $U^{\prime}>0$ and $U^{\prime \prime}<0$. Einally, as in Newbery and Stiglitz, the indirect utility function of the representative consumer is assumed to take the following form:

$$
V(I, p, q)=\begin{array}{ll}
\frac{\left(I p^{-a} q^{-b}\right)^{t-p}}{1-p} & \text { for } \rho \neq 1 \\
\log I-a \log p-b \log q & \text { for } p=1
\end{array}
$$

where $\rho$ is the coefficient of relative risk aversion. This leads to aggregate (domestic) demand functions for the risky $\left(Q_{r}\right)$ and safe $\left(Q_{s}\right)$ commodities of $Q_{r}=\frac{a m I}{p}$ and $Q_{s}=\frac{b m I}{q}$.

The domestic government controls the volume of international trade through the use of trade quota licenses, whlch it issues (free of charge) to foreign producers allowing them to export to the home market, and to domestic producers 
allowing them to export abroad. To model this, we define $T$ as the fraction of one country's excess of risky commodity production over the other country's that can be exported under the chosen quota levels. Then the domestic government chooses $T$, which ranges from zero to one half, with $T=0$ corresponding to autarky and $T=1 / 2$ corresponding to free trade.

For any choice of $x$, the volume of trade allowed under the quota system will directly affect the behavior of equilibrium goods prices, as can be seen by equating commodity demand in the domestic market to commodity supply available there, or

$$
\frac{a m I}{p}=n x \theta+T \cdot\left[n x \theta^{*}-n x \theta\right], \quad \frac{b m I}{q}=(1-x) n
$$

Rearranging (3) and using the relationship between $\theta$ and $\theta^{*}$ yields

$$
p=\frac{a y}{x[0+2 T(1-\theta)]}, \quad q=\frac{b y}{1-x}
$$

where $y=\frac{m I}{n}$. At the same time, the choice of $T$ will effect commodity prices $p$ and $q$. Indirectly as well, through its effect on the producer choice of $x$ that solves (1). Einally, to keep the problem simple, we assume that all capital in the domestic production sector is owned by foreigners, so that the domestic government cares only about the welfare of domestic consumers when choosing $T$. As we will see, this assumption turns the problem into one in which the government chooses trade policy in an attempt to address a domestic production distortion that arises under free trade.

Consider now the domestic government's optimal choice of trade policy T. If it were to choose a policy of autarky $(\mathrm{T}=0)$ and producers believed this announcement, then all risk would be borne by consumers, and the allocation of 
resources between the risky and safe commodity would be determined by (1) as $\hat{x}(T=0)=\frac{a}{a+b}$. But for any choice of trade policy $T \varepsilon[0,1 / 2]$, the choice of $x$ that maximizes consumer utility, i.e., which solves $\frac{\partial V}{\partial x}=0$, is also $\frac{a}{a+b}$, so that only expecting autarky would producers choose the allocation of resources that is best for consumers. As $T$ is increased from 0 toward $1 / 2$, the risk is shifted from consumers to producers, and producers find it optimal to reduce $x$ from $\frac{a}{a+b}$, and move resources out of the increasingly risky sector. This resource allocation effect is, to domestic consumers, a cost of freer trade which must be weighed against the benefit that results as consumers face less risk (price variability). It is the effect of trade on producers' choice of $x$ that enables Newbery and Stiglitz to find parameter values under which free trade is Pareto inferior to autarky. More generally, free trade $(T=1 / 2)$ will not be optimal as a result of this effect, and some degree of protection will be chosen as the optimal policy.

Consider, however, the choice of $T$ made by the domestic government when it is unable to influence producer decisions about $x$ by precommiting to a particular trade policy $T$, and is forced into a time consistent equilibrium. The time consistent level of trade will occur at a value of $T$ for which the domestic government has no incentive to surprise producers with a different trade level. But caring only about domestic consumers, any announced level of protection $\left(T<\frac{1}{2}\right)$ will leave the government with an incentive to surprise producers with free trade $\left(T=\frac{1}{2}\right)$ since, with $x$ held fixed, the movement to free trade can only benefit domestic consumers by eliminating the risk they face. Free trade is the unique time consistent equilibrium. 
As such, a government that maintains flexibility of its trade policy relative to the decisions of domestic producers would in this case find itself trapped in the time consistent free trade equilibrium. Trade policy discretion will, in this case, lead the government to allow too much trade and could, under the kinds of parameterizations described by Newbery and stiglitz, result in trade freely occurring between countries even though ali participants would be better off in its absence.

\section{Generalizations and Extensions}

The results of the previous sections were based on a one shot game. Moreover, the extensive form of such a game assumed that trade policy was set in between production and consumption decisions.

The normative results concerning the suboptimality of discretion and the ambiguity of the rankings of alternative instruments are robust to several extensions of the underlying framework, as long as some economic decision is made before observing the trade policy action. If the game were repeated over time, however, the government might face reputational incentives. As is well known from the macroeconomics literature, such reputation mechanisms could reduce the severity of the time inconsistency problem. The plausibility of reputational equilibria however is stili an open issue (see, for instance, the survey by Rogof $(1987))$.

The positive results presented in the previous sections, on the other hand, are more sensitive to the detalls of the timing assumptions. In an explicitly dynamic model, for instance, the decisicns concerning savings and the purchase of consumer durables would be based on the expectations of future trade policy. 
Hence, the government would have the opportunity of surprising consumers as well as producers. Alternatively, the government might take its trade policy actions after some production decisions but before others, so that the opportunity to surprise would exist only with respect to a subset of the production decisions. An example is the labor-leisure choice mentioned in footnote 3 . In these cases, the nature of the incentive compatability condition, and hence the positive properties of the time-consistent equiliorium, would reflect the details of the timing assumptions. As a consequence, the clear and simple positive results in the general analysis of Section II could be overturned. Acknowledging these complications, however, does not diminisin the relevance of our positive results for the class of problems that are broadly consistent with the simple timing assumptions maintained above. Nor does it weaken our main point: the secondbest nature of trade policy intervention suggests that the issue of time consistency will be an important consideration in determining the extent as well as the efficacy of such policy intervention in most environments.

\section{Concluding Remarks}

The general analysis and examples of the previous sections point out that increasing the discretion and flexibility of the government decision process may be counterproductive. Many of the same market imperfections that motivate trade policy intervention can also generate time inconsistencies in the implementation of the optimal activist policies. Whenever this happens, a government pursuing a discretionary trade policy finds itself trapped in a suboptimal equilibrium. Thus, a commitment to a simple set of trading rules may be superior to an activist but discretionary trade policy. 
It is not surprising that these conclusions resemble those of the debate on rules versus discretion in macroeconomic policy: a careful analysis of the government incentives is bound to find that the scope of economic policy (whether trade, monetary, or public finance policy) is limited by the government's ability to influence private sector expectations. This is why the government can benefit by being endowed with the possibility of entering into binding commitments. In the case of trade policy, however, and in contrast to other aspects of economic policy, institutions capable of enforcing these commitments may be more readily available. Existing international organizations, like the GATT, were originally conceived to facilitate international cooperation among individual countries. The results of this paper suggest that these institutions can--and presumably to some extent already do--perform an equaliy crucial role in enforcing the cooperative outcome in a setting in which the strategic interaction is between each government and the private sector at home or abroad. 


\section{Footnotes}

1' For instance, Dixit (1987) concludes, "The current median view of the profession in this matter can be fairly characterlzed as (i) a recognition that the existence of imperfect competition does modify or overturn some conventional beliefs about trade policy, and (ii) an awareness that the design of policy to flt each situation requires close attention to its specific details. This suggests that research should be directed toward improving our understanding of the realities of some industries that are likely candidates for strategic trade policies."

$2^{\prime}$ It is well known that for a distorted small open economy trade policy is generally not the first best tool. Unless a two-part tariff policy can be used, a tariff is also not first best for a large open economy, since it leaves some monopoly rents unexploited. Hence, in this case too, the government lacks a policy instrument.

3' For simplicity, we abstract from the labor/leisure choice in what follows. The natural way to introduce this decision would be to treat it as a consumption decision, 1.e., made after having observed the government policy. This would complicate the analysis by providing the government with the opportunity to surprise only with respect to a subset of production decisions. See Section $V$ for a discussion of how this would effect our results.

4/ The literature on trade policy intervention focuses on the use of tariffs to correct distortions that fall within the traded sector, a focus that we adopt here as well. Introducing a nontraded sector leaves the entire analysis qualitatively unaffected as long as the distortion remains within the traded goods sector and that production decisions in the nontraded 
sector are made prior to the government policy move. On the incorporation of nontraded goods into the traditional analysis of tariffs, see hoodland $(1982)$

5' See, for example, Bhagwati (1971).

6/ See, for example, Bhagwati (1971).

I' While (i), (ii) and (iii) consider the time consistency of tariff intervention in the presence of distortions that keep the economy from the Pareto optimum, the use of tariffs to pursue so-called "non-economic" objectives with regard to consumption, production, or trade would run into exactly analagous problems.

8/ A more detailed analysis can be found in stalger and Tabellini (1987). Eaton and Crossman (1985) show that such a policy can be optimal ex-ante, in the sense that it can achieve some beneficial risk sharing between $r i s k$ averse individuals when insurance markets are incomplete. See Dixit (1987), however, for a recent challenge to this view. An alternative motivation for the use of tariffs as redistributive devices could come from a political economy perspect ive. 


\section{References}

Bhagwati, J. "The Generalized Theory of Distortion and Welfare," in "Trade, Balance of Payment and Growth," edited by Bhagwati, J., R. James, R. Mundell, J. Vanek: North Holland, 1971.

Dixit, Avinash, "Trade and Insurance with Moral Hazard," Journal of International Economics, November 1987.

Dixit, Avinash, "Strategic Aspects of Trade Policy," in Advances in Economic Theory: Fifth World Congress, Truman F. Bewley, editor, Cambridge University Press, New York, 1987, pp. 329-362.

Eaton, J. and G. Crossman, "Tariffs as Insurance: Optimal Commercial Policy when Domestic Markets are Incomplete," Canadian Journal of Economics, May 1985.

Kydiand, $E$. and E. Prescott, "Rules ratrer than discretion: the inconsistency of optimal plans," Journal of Political Economy, 1987.

Lapar, Harvey E., "The Optimal Tariff, Production Lags and Time Consistency," forthcoming, American Economic Review.

Newbery, D.M.G., and J.E. Stiglitz, "Pareto Inferior Trade," Review of Economic Studies, 1984.

Rogoff, N. "Constitutional Constraints on Monetary Policy'" Carnegle-Rochester Conference Series on Public Policy, Spring 1987.

Staiger, R, and G. Tabellini, "Discretionary Trade Policy and Excessive Protection," American Economic Review, December 1987.

Woodland, A., International Trade and Resource Allocation (North-Holland: Amsterdam, 1982 
Figure 1

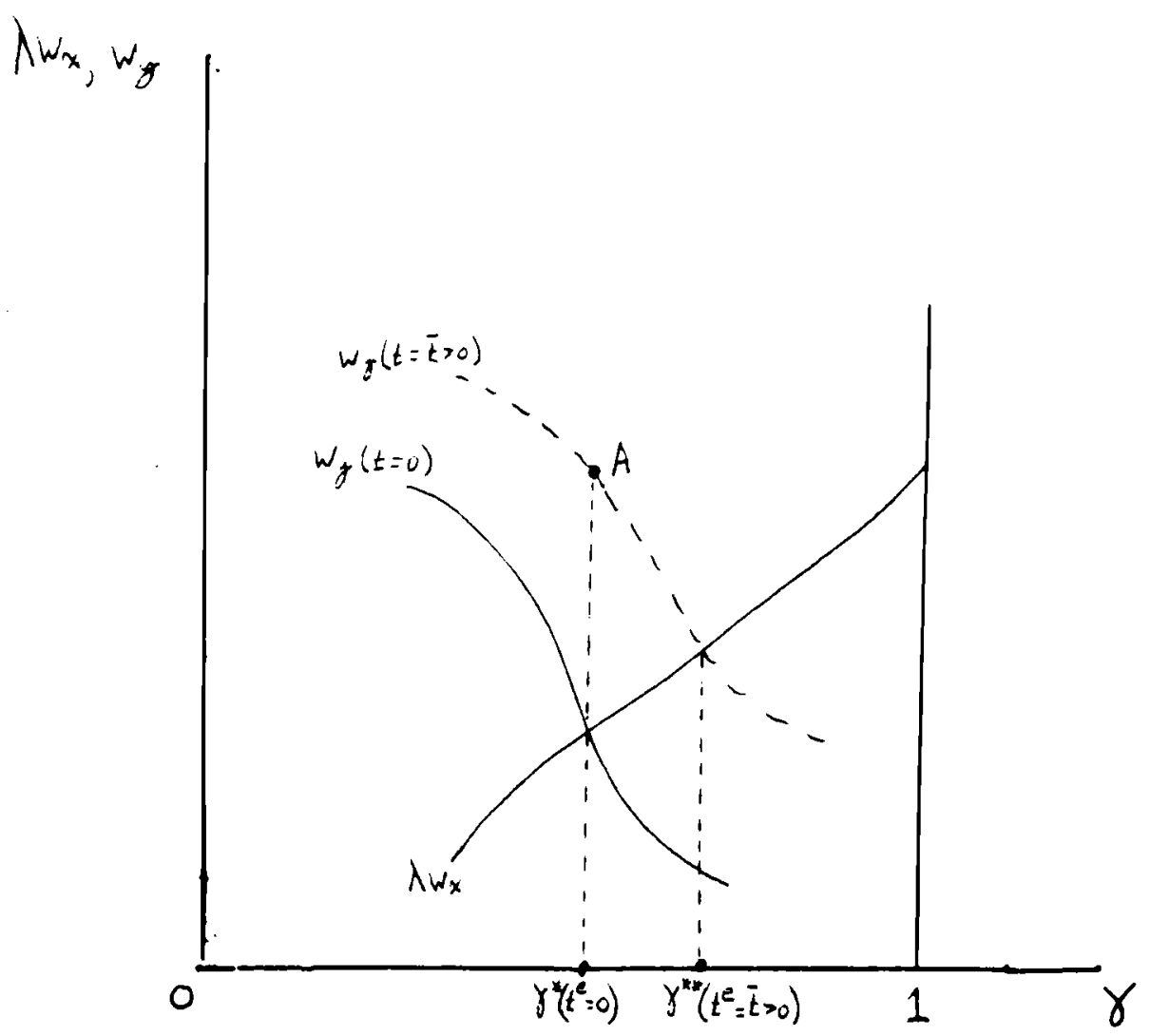

